\title{
Dinâmica metropolitana e estrutura social em Salvador
}

\author{
INAIÁ MARIA MOREIRA DE CARVALHO \\ PAULO HENRIQUE DE ALMEIDA \\ JOSÉ SÉRGIO GABRIELLI DE AZEVEDO
}

RESUMO: Este artigo discute como a dinâmica da globalização e mudanças a ela associadas vêm afetando a conformação socioeconômica das metrópoles brasileiras, analisando, especificamente, o caso de Salvador. Após uma referência inicial à literatura sobre os processos em discussão, o texto assinala como a análise das reconfigurações espaciais e urbanas, no Brasil, não pode deixar de lado a herança histórica do processo de urbanização, a diferenciação da rede urbana e metropolitana e os efeitos espaciais e sociais das políticas recentes de inserção do país na nova ordem mundial. Analisa, a seguir, a trajetória e as transformações socioeconômicas recentes de Salvador, constatando como as mesmas são bastante similares às verificadas em outras metrópoles brasileiras, com efeitos adversos ampliados pelas condições e especificidades locais.

\section{Introdução}

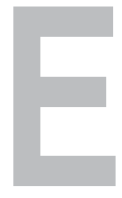

ste trabalho discute os efeitos da globalização e da reestruturação produtiva sobre a conformação socioeconômica das metrópoles brasileiras, analisando, particularmente, a trajetória recente da Região Metropolitana de Salvador.

Este tema adquiriu uma inquestionável relevância na agenda atual da pesquisa urbana, tendo em vista a dimensão e os impactos dessa reestruturação sobre os diversos territórios e sociedades, no curso do denominado processo de globalização (cf. Ribeiro, A.C., 2000; Veiga, 2000).

Professora de PósGraduação em Ciências Sociais da UFBa e Pesquisadora do $\mathrm{CRH}$

Professor do Curso de Mestrado em Economia da UFBa

Professor do Curso de Mestrado em Economia da UFBa 
Este texto foi incluído na coletânea $O$ novo rosto da América Latina: cidade, planejamento e ação, organizado por Ana Clara Ribeiro, que se encontra em vias de publicação em Buenos Aires, pelo CLACSO. A versão atual apresenta modificações (como o próprio título), incorporando críticas e sugestões de pareceristas anônimos da Tempo Social, a quem os autores agradecem nesta oportunidade.
Como se sabe, esse processo vem sendo marcado por um intenso avanço tecnológico e por transformações radicais nos padrões de produção, comercialização e consumo; por uma tendência à circulação cada vez mais ampliada de capitais e mercadorias, assim como por uma desmaterialização crescente da riqueza; pela conformação de um mercado mundial e pelo enfraquecimento das instâncias reguladoras constituídas em escala nacional, com a expansão e incremento do poder de interesses e grupos transnacionais que se superpõem às fronteiras entre países, pressionando pela redução dos "entraves" à sua livre circulação e maior lucratividade, com a redução de barreiras alfandegárias e a desregulamentação e flexibilização dos mercados; e, também, por uma utilização e uma reconfiguração dos territórios, que alteram radicalmente o valor dos lugares e da sua gente (cf. Santos, 2000).

As novas tecnologias e padrões de produção viabilizaram uma enorme mobilidade de capital em escala global, reduzindo o papel dos Estados e afetando a congruência das economias nacionais. Seus fluxos dinâmicos articulam, agora, espaços descontínuos, redefinindo territórios e regiões e vinculando áreas distantes, de tal forma que condições locais passam a ser definidas por processos e eventos globais. Constituem-se, também, novas centralidades e exclusões, na medida em que a dinâmica da globalização integra de forma bastante seletiva os diversos países, regiões e localidades, incorporando e dinamizando algumas áreas (ainda que os benefícios dessa dinâmica se distribuam de forma parcial e restrita) e afetando negativamente ou marginalizando outras (cf. Soja, 1993).

Tais fenômenos vêm tendo um impacto decisivo sobre a estrutura econômica e social das áreas metropolitanas (onde se concentra, na grande maioria dos países, o aparato produtivo, a riqueza, o poder e a população), sobre as condições e a qualidade da vida urbana, as desigualdades, a pobreza e as mobilizações políticas e sociais. Inserindo-se com destaque na agenda das questões contemporâneas, essas transformações têm despertado a atenção dos planejadores e da comunidade acadêmica, entre outros segmentos, suscitando diversos estudos e reflexões.

No plano internacional esses estudos têm privilegiado os vínculos entre o local e o global (o espaço glocal), valorizados por novas propostas e modelos de gestão urbana, bem como o debate sobre as denominadas " global cities". Esse debate ressalta a constituição de uma rede mundial de cidades que oferecem condições especiais para as atividades de comando de negócios, onde se concentrariam o poder econômico, a sede das grandes corporações, o controle dos meios de comunicação e os serviços produtivos modernos, circulariam os maiores fluxos de informação, capital e recursos e seriam tomadas as grandes decisões econômicas, tornando-se cada vez mais estratégicas para o capital global. Este processo é simultâneo a uma polarização crescente entre estes espaços e o resto do mundo, bem como a um aumento das diferenciações internas em cada uma das regiões. 
Autores como Sassen (1991), Reich (1991) e Borja \& Castels (1997), por exemplo, analisam as transformações que estariam ocorrendo nessas cidades, com o declínio da atividade industrial, a expansão das atividades financeiras e dos serviços e a mudança do seu papel, tendo como hipótese básica a existência de vínculos estruturais e necessários entre a globalização dessas metrópoles e a intensificação da sua dualização social. Com a segmentação do mercado de trabalho, as transformações assinaladas produziriam uma nova estrutura social, marcada pela polarização entre categorias superiores e inferiores da hierarquia social e pela concentração de renda, assim como pela redução das camadas médias. Refletindo-se no plano espacial, isto produziria, também, uma dualização das estruturas urbanas.

Essas hipóteses, no entanto, parecem não resistir ao confronto com a realidade. Pesquisas efetuadas em metrópoles como Paris, Londres, Madri, Rio de Janeiro, Buenos Aires e Santiago não confirmam a substituição da estrutura de classes da sociedade industrial por uma polarização entre os mais ricos e os mais pobres nem a dualização do espaço urbano que lhe estaria associada. Como assinala Ribeiro (2000), paralelamente a fenômenos comuns, como a redução do proletariado industrial, o crescimento do setor dito "terciário" e do emprego em serviços (em atividades de alta e baixa qualificação), o empobrecimento de zonas centrais, mudanças de função em algumas áreas da cidade e uma auto-segregação das elites, que tendem a se isolar em enclaves residenciais e em outros espaços exclusivos, as pesquisas evidenciam uma certa estabilidade das estruturas sociais e urbanas dessas cidades.

Em defesa dos autores que prevêem uma crescente (re)polarização social, poderia se dizer que estamos em um período de significativa transição, sendo natural que características das estruturas urbanas anteriores coexistam com novas tendências e mudanças pouco aparentes.

O que fica claro é a inexistência de uma trajetória única e de tendências universais e inexoráveis para as cidades globais e, menos ainda, para as grandes metrópoles de caráter mais nacional, na medida em que a globalização constitui um fenômeno inacabado, contraditório e de efeitos seletivos sobre os diferentes territórios, comandado por forças transnacionais mas dependente, também, de condições políticas e decisões nacionais e locais. Esta negação da trajetória única exige a avaliação das especificidades locais para perceber as diferenças dos impactos internos da abertura e do ajuste, considerando que diferenças nas trajetórias históricas e na configuração das cidades, instituições, características e atores nacionais e locais também interferem de forma relevante sobre a dinâmica e os efeitos das mudanças em discussão.

Apresentando estudos sobre cidades européias e latino-americanas, a coletânea organizada por Ribeiro (2000) é bastante ilustrativa a esse respeito. Discutindo as relações entre globalização e metropolização em Santiago do Chile, por exemplo, Mattos (2000) assinala como a mudança no padrão de desenvolvimento do país ocasionou uma redução do emprego na indústria e no setor público. A recuperação econômica e a expansão dos serviços, porém, 
viabilizaram um aumento geral do emprego e da renda per capita, naquela cidade, com a persistência do padrão de desigualdade social e da distribuição regressiva de renda, uma vez que a precarização e a informalidade constituem atributos significativos do mercado de trabalho local. Já no caso de Madri, estudado por Maldonado (2000), a redução do emprego industrial foi compensada por um considerável aumento da ocupação nas atividades de serviços empresariais (como aquelas ligadas à produção e às finanças) e nas de serviços públicos ou de consumo social, como saúde e educação, com uma absorção de profissionais mais qualificados. Isto se traduziu em um aumento numérico das classes médias, assim como em menores desigualdades na distribuição de renda. Em Paris a dualização não foi constatada (cf. Preteicelle, 2000), nem também no Rio de Janeiro. Conforme Ribeiro (2000), dos anos 80 para os anos 90 a estrutura ocupacional dessa última metrópole foi marcada pela redução do operariado industrial (em termos absolutos e relativos), pelo crescimento dos ocupados em atividades terciárias e do sub-proletariado urbano. A precarização dos vínculos ocupacionais e o empobrecimento do conjunto dos trabalhadores ampliaram as desigualdades na distribuição de renda. Paralelamente, porém, houve um forte incremento da elite intelectual (ao lado de uma redução da elite dirigente) e a ampliação e importância das classes médias na estrutura social daquela região metropolitana chamam a atenção.

A inexistência de uma trajetória única, todavia, não implica a inexistência de mudanças comuns à maioria das metrópoles contemporâneas. Como os próprios textos da coletânea de Ribeiro sugerem, a terciarização crescente da economia das grandes cidades é talvez o mais importante desses movimentos. Nesta direção, Bonamy e May (1994), Hansen (1994) e Philippe, Léo \& Boulianne (1998), entre outros, têm mostrado como os processos de crescimento metropolitano vão sendo modificados pela expansão das novas atividades de serviços e como esta expansão tem provocado mudanças importantes na configuração espacial e na estrutura de emprego de grandes cidades européias e norte-americanas. Este processo tem muito a ver com a prévia relação inter-setorial, a profundidade das cadeias nacionais de fornecedores e a velocidade e intensidade dos processos de abertura comercial, desmontando setores já existentes e deslocando segmentos sociais integrados para a área de exclusão. A flexibilização dos mercados de trabalho e a informalização das relações de emprego constituem uma outra face deste mesmo processo.

Por outro lado, no caso do Brasil, a análise das reconfigurações espaciais e urbanas não pode deixar de lado a herança histórica de um processo de urbanização marcado pela rapidez e pela exclusão social, a diferenciação da rede urbana e metropolitana dela resultante ou as características e efeitos espaciais e sociais do chamado "ajuste estrutural" e das políticas recentes de inserção do país na nova ordem mundial.

O processo de urbanização e de industrialização do Brasil, com a constituição de uma economia e de um mercado nacional integrado, produziu uma divisão interregional do trabalho que cristalizou e aprofundou desigual- 
dades espaciais existentes desde o início da sua história. Contudo, entre as décadas de 60 e de 80, preocupando-se com o surgimento de conflitos sociais, com a integração e unidade do país e com a promoção do seu desenvolvimento, o Estado nacional tomou algumas iniciativas e formulou certas políticas para incentivar o crescimento de regiões mais pobres e menos dinâmicas, como o Nordeste, e para a ocupação das fronteiras. Em decorrência de políticas explicitamente regionais, dos efeitos espaciais de certas políticas setoriais e da presença de grandes empresas estatais, registrou-se, então, uma certa tendência à descentralização da produção e da indústria, com o surgimento de pólos dinâmicos em áreas estagnadas que beneficiaram algumas capitais, ainda que a produção e a riqueza nacional permanecessem bastante concentradas nas regiões Sudeste e Sul e em um pequeno número de estados da Federação. No caso do Nordeste este movimento favoreceu especialmente a Região Metropolitana de Salvador, mais integrada inter-setorialmente com as necessidades do parque industrial do Centro-Sul. As regiões metropolitanas de Recife e de Fortaleza também cresceram, mantendo, porém, uma dinâmica menos acelerada e determinada mais endogenamente.

Como seria de esperar, essas desigualdades se refletem na rede urbana, que apresenta uma enorme heterogeneidade. Estudo recente sobre as suas características e perspectivas (cf. IPEA/UNICAMP/IE/NESUB/IBGE, 1999) considera a existência de três grandes estruturas urbanas no país - Centro-Sul, Nordeste e Centro-Oeste - com doze subsistemas regionais comandados por treze metrópoles. Analisando a composição e as condições das estruturas, subsistemas e metrópoles assinaladas, o estudo ressalta a sua grande diversidade em termos de configuração espacial, densidade, estrutura produtiva, dotação de infra-estrutura e serviços básicos, dinâmica populacional, condições de vida e perspectivas de desenvolvimento. Essa diversidade não apenas interfere sobre as possibilidades e modalidades de incorporação das diferentes áreas e centros urbanos aos novos fluxos dinâmicos como, também, tende a ser por eles reforçada nos anos 90 .

Essa questão é destacada por estudos como os de Araújo (1995 e 1999), Lavinas, Garcia \& Amaral (1997), IPEA/UNICAMP/IE/NESUB/IBGE (1999) e Diniz (2000), constatando uma interrupção na última década do processo de descentralização econômica verificado em décadas anteriores e uma tendência à reconcentração do dinamismo em certas áreas e metrópoles, privilegiando o Sudeste e o Sul do país, com a reconfiguração do padrão de desenvolvimento brasileiro e a implementação de um conjunto de políticas convergentes, recomendadas pelas agências multinacionais.

Denominadas como "ajuste estrutural", "reformas estruturais" ou "reformas orientadas para o mercado", elas envolvem a realização de uma abertura comercial intensa e rápida, a implementação de um programa de privatizações, ênfase nos mecanismos de mercado e uma profunda reformulação no papel do Estado, não apenas em termos do seu papel econômico e de suas funções reguladoras como, também, de suas responsabilidades 
enquanto provedor de políticas econômicas e sociais (cf. Souza e Carvalho, 1999). Além dos impactos da acelerada e generalizada abertura comercial, um outro fator com efeitos desiguais nas regiões foi o processo de privatização. Nas metrópoles nordestinas o papel das empresas estatais era bem mais relevante do que naquelas do Centro-Sul.

A nova ênfase na competitividade e na integração dos espaços dinâmicos do país ao mercado externo soma-se à ausência ou ao encolhimento de iniciativas e políticas governamentais de caráter industrial ou regional que pudessem atenuar os impactos seletivos das transformações em apreço, compatibilizando-as, de alguma forma, com a integração nacional. Regionalismos e políticas tradicionais, afirmadoras de uma unidade de interesses comuns, são substituídos por um localismo de caráter fragmentador, que busca suas próprias definições e alternativas e disputa investimentos e empregos através da "guerra fiscal" e da oferta de vantagens crescentes aos setores empresariais (cf. Araújo, 1995 e 1999, Costa, 2000).

Na verdade, a "guerra fiscal" constitui uma tentativa de resistência passiva e isolada dos governos estaduais e municipais aos novos fatores determinantes da (des)localização industrial. A nova indústria e os novos serviços sãofootloose, vale dizer, dotados de uma mobilidade locacional muito maior, garantida pela redução do custo do capital fixo, pelas novas tecnologias de informação e telecomunicação e pela terceirização de atividades anteriormente internalizadas. As firmas que se modernizam têm assim menores "custos de saída" para abandonar regiões e cidades onde enfrentam o que consideram como deseconomias externas ou de aglomeração, conceito que abrange fatores diversos, dos engarrafamentos urbanos aos sindicatos combativos.

Nessas circunstâncias, ocorre uma reconfiguração econômica e espacial de impactos decisivos sobre as estruturas urbanas e metropolitanas, tornando obsoletas vantagens locacionais comparativas do passado, deixando à margem diversas áreas do país e privilegiando outras, a partir da lógica das grandes empresas transnacionais e dos capitais e interesses a ela associados e do novo padrão de desenvolvimento. Como já foi mencionado, isto favorece espaços e cidades que acumularam certas vantagens e que podem atender melhor aos requisitos da denominada "acumulação flexível", como a disponibilidade de centros de produção de conhecimento e tecnologia, uma dotação mais ampla e diversificada de infra-estrutura, uma oferta diferenciada de serviços empresariais, proximidade dos mercados de alta renda e dos "nós" dos fluxos globalizados.

A necessidade e relevância de estudos sobre os efeitos da reestruturação produtiva sobre o território e sobre a dinâmica e as condições das áreas metropolitanas (cenário atual de vida para uma grande parcela da humanidade) tornou-se consensual nas discussões sobre a agenda atual da pesquisa urbana. No Brasil eles ainda são escassos, merecendo destaque os que vêm sendo efetuados pelo Projeto Metrópoles, Desigualdades Sócio-Espaciais e Governança Urbana. Dialogando com a literatura internacional e 
utilizando amplamente dados censitários e outras informações, este projeto vem analisando as condições de São Paulo, Belo Horizonte, Rio de Janeiro e Porto Alegre, abordando questões como a reconfiguração espacial e a segregação urbana, a exclusão social, a implementação de políticas públicas e os novos padrões de gestão, e, no caso do Rio de Janeiro e de Porto Alegre, as permanências e mudanças na estrutura ocupacional e social (cf. Bogus e Ribeiro, 1999/2000 e Ribeiro, 2000).

É claro, porém, que as conclusões dessas pesquisas não podem ser generalizadas para o conjunto das metrópoles brasileiras.

Situadas nas regiões mais desenvolvidas do país, aquelas capitais possuem estruturas produtivas densas, diversificadas e dinâmicas e condições privilegiadas em termos das transformações atuais. Rio de Janeiro e São Paulo vêm se configurando como cidades globais e gateway cities, concentrando as sedes de grandes empresas, o capital financeiro e os serviços modernos, os centros de informações e decisões, pelo seu papel de "intermediadoras" e principais elos de ligação da economia do Brasil e de outras áreas da América Latina com os centros e fluxos do capital global (cf. Marques e Torres, 2000). Porto Alegre possui outras especificidades (cf. Mamarella, 2000), como uma qualidade de vida superior, o que hoje se constitui em vantagem competitiva muito importante. Assim, cabe multiplicar os estudos e as comparações, para o que o presente trabalho pretende contribuir discutindo o caso de Salvador, cuja trajetória e configuração presente são bastante ricas e instigantes para a presente discussão.

\section{A trajetória de Salvador}

Demograficamente, Salvador é a terceira maior cidade brasileira, com perto de 2,5 milhões de habitantes e uma área metropolitana classificada como a sexta do país. Fundada no início do período colonial, com funções políticoadministrativas e mercantis, ela sediou o governo geral do Brasil até 1763. Mas com a transferência da capital do país para o Rio de Janeiro, o declínio da base agro-exportadora local e, posteriormente, a constituição de um mercado unificado nacionalmente e a concentração industrial no Centro-Sul, a cidade foi afetada negativamente, experimentando um longo período de estagnação econômica e populacional. Essa estagnação só começou a ser superada na década de 1950, com a descoberta e exploração de petróleo no Recôncavo baiano, por algumas décadas responsável pela maior parte da produção nacional.

Com um volume de investimentos sem paralelo na história da economia do estado, a Petrobrás elevou o emprego industrial, a massa de salários e o montante de renda, estimulando o surgimento de algumas indústrias complementares à empresa, a construção civil, o comércio e os serviços e desencadeando um processo de significativo crescimento populacional, econômico e urbano em Salvador e nas franjas da cidade, constituindo o que hoje se denomina como a sua região metropolitana. Em fins da década de 60 essa área também passou a receber alguns investimentos industriais incentivados pela SUDENE. Mais re- 
centemente, dos anos 70 para os 80 , os esforços desenvolvimentistas do governo federal para complementar a matriz industrial brasileira, com a produção de insumos básicos e bens intermediários, aproveitaram vantagens locacionais existentes para a implementação do Pólo Petroquímico de Camaçari, que se converteu no foco dinâmico da economia regional, comandando a expansão e a diversificação da sua estrutura produtiva.

Esses fenômenos tiveram um impacto extraordinário sobre os municípios da Região Metropolitana de Salvador (RMS) e, especialmente, sobre a velha capital baiana. Em 1950 a cidade possuía apenas 393 mil habitantes. Entre 1950 e 1970, esta população mais que duplicou, atingindo 1 milhão de pessoas. Nas décadas seguintes, as taxas de crescimento começam a diminuir, mas muito lentamente, situando-se ainda entre 3 e $4 \%$ ao ano. Com isso a população atingiu quase 1,5 milhão em 1980 e superou os 2 milhões no início dos anos 90. Em 2000, seus 2,5 milhões de habitantes se somam aos mais de 600 mil residentes de outros municípios da sua Região Metropolitana, formando - em termos demográficos - um dos seis mais importantes mercados regionais do país. Como em outras regiões metropolitanas brasileiras, na década de 90, a população cresce muito mais nas áreas periféricas do que nas zonas centrais, com implicações muito importantes em termos das pressões sobre a infra-estrutura urbana e as necessidades sociais.

A expansão e as transformações do tecido urbano foram também radicais. $\mathrm{O}$ crescimento da indústria e dos serviços incidiu sobre uma região urbana pobre e incipiente, polarizada por uma cidade praticamente estagnada ao longo de várias décadas, exigindo sua transformação. Isto se deu de forma bastante rápida e abrupta, entre as décadas de 60 e 70, com a realização de grandes obras que acompanharam e anteciparam os vetores da expansão urbana. Comprometida com uma modernização excludente e com os interesses do capital imobiliário, a Prefeitura de Salvador, que detinha a maioria das terras do município, transferiu sua propriedade para (algumas poucas) mãos privadas através da Lei da Reforma Urbana. Promoveu uma ampliação substancial do sistema viário com a abertura das avenidas de vale, extirpando do tecido urbano um conjunto significativo de assentamentos de população pobre, que ocupavam tradicionalmente os fundos até então inacessíveis dos numerosos vales de Salvador, enquanto as classes médias e altas residiam nas suas cumeeiras. Além disso, erradicou invasões populares localizadas na orla marítima, área reservada ao turismo, outro componente da estratégia de crescimento e modernização da cidade (cf. Brandão, 1981; Souza, 2000).

Essas intervenções, associadas à realização de investimentos complementares, pesados e seletivos (centrados na infra-estrutura e no projeto industrial, deixando para um futuro indefinido o atendimento das carências sociais e dos equipamentos e serviços de consumo coletivo) interferiram decisivamente na conformação de um novo padrão de produção do espaço urbano, com a configuração de três vetores bem diferenciados de expansão da cidade: a orla marítima norte, o "miolo" e o subúrbio ferroviário no litoral da Baía de Todos os Santos. O primeiro 
constitui a "área nobre" da cidade, local de moradia, serviços e lazer, onde se concentram a riqueza, os investimentos públicos, os equipamentos urbanos e os interesses da produção imobiliária. O segundo, localizado no centro geográfico do município, começou a ser ocupado com a implantação de conjuntos residenciais para a "classe média baixa" na fase áurea do Sistema Financeiro de Habitação, tendo a sua expansão continuada por loteamentos populares e invasões, com uma disponibilidade de equipamentos e serviços bastante restrita. Finalmente, o subúrbio ferroviário transformou-se na área mais carente e problemática da cidade, concentrando uma população extremamente pobre em loteamentos populares e invasões, marcados pela precariedade habitacional, pelas deficiências de infra-estrutura e serviços básicos e, mais recentemente, por altos índices de violência (cf. Franco, Santos \& Gabrielli, 1998, Carvalho \& Pinho, 1996, Souza, 2000). Assim, a segregação sócio-espacial da pobreza se consolidou e intensificou com o surgimento da Salvador moderna.

A dinâmica e as transformações assinaladas refletiram-se igualmente sobre a estrutura ocupacional e social da cidade e da sua região. Apesar dos seus reduzidos vínculos com os demais setores da economia baiana, os investimentos industriais na RMS, concentrados na petroquímica, estimularam, direta e indiretamente (via gasto público estadual e transferências federais), o surgimento de novas atividades e a expansão e modernização de outras. A administração pública ganhou maior peso, o varejo acelerou sua renovação com a multiplicação de shopping centers e supermercados, os serviços de consumo coletivo (notadamente educação e saúde) e outros serviços de consumo intermediário ou final (engenharia, transporte, telecomunicações) conheceram significativo desenvolvimento. Com isso, as atividades agropecuárias perderam qualquer importância na RMS, enquanto o emprego urbano avançou em participação, com o surgimento de novas empresas e a criação de várias instituições públicas, estatais ou sociais, concentradas em Salvador.

As classes médias (até então reduzidas) se ampliaram e diversificaram, com o crescimento de empregados de escritório e uma maior demanda de técnicos e de profissionais de qualificação superior, como administradores, economistas, engenheiros, contadores, advogados, professores e profissionais de saúde.

O emprego na indústria de transformação se expandiu, principalmente a partir da implementação do Complexo Petroquímico de Camaçari, que em pouco mais de sete anos criou cerca de 20.000 empregos diretos (levando à emergência de um operariado industrial moderno, com maior qualificação, salários e benefícios bem mais elevados que a média local), além de outros 25.000 indiretos nas empresas prestadoras de serviço. Contudo, o perfil dessa indústria automatizada, voltada para a produção de insumos básicos destinados à indústria do Sudeste do país, e a exiguidade do mercado consumidor regional (pouco atrativo para investimentos com maior capacidade de absorção de mão-de-obra, como a indústria de bens de consumo final) mantiveram a parcela de trabalhadores ocupados nesse setor bem mais reduzida do que em outras metrópoles brasileiras. 
Além disso, as transformações assinaladas incidiram sobre um mercado de trabalho marcado por uma super oferta de mão-de-obra de baixa qualificação, reforçada pela atração de fluxos migratórios para Salvador e sua área metropolitana, pela vinculação de uma grande parcela de força de trabalho a ocupações precárias e de baixa remuneração e por uma oferta restrita de postos de trabalho de qualidade, socialmente protegidos, com salários mais elevados e possibilidades de ascensão profissional (cf. Carvalho \& Souza, 1980, Borges e Filgueiras, 1995, Borges, 1996). No entanto, é preciso ser cuidadoso. A questão da oferta de trabalho na RMS se distingue do que ocorre em outras regiões metropolitanas brasileiras. As hipóteses referentes a uma maior mobilidade da oferta de trabalho não parecem encontrar evidências empíricas significativas, uma vez que na RMS o crescimento da população em idade ativa (PIA) não parece ser distinto do de outras áreas. Como explicar taxas maiores de desemprego na RMS, se a expansão da PIA é semelhante? Ao mesmo tempo, a população economicamente ativa (PEA) vem se reduzindo nos últimos anos em relação à PIA, muito mais que em outras regiões, o que seria contraditório com a hipótese de um desemprego provocado por excesso de oferta de trabalho. Assim, o crescimento do desemprego parece estar mais associado a uma insuficiência na criação de novos postos de trabalho para absorver aqueles deslocados do mercado que não se movimentaram em direção à inatividade (cf. Azevedo, 2000; Almeida e Azevedo, 1999a).

Ainda que esses problemas não chegassem a ser superados, a expansão e a diversificação da estrutura produtiva da RMS e o processo de crescimento que persistiu até meados da década de 80 ampliaram as oportunidades de trabalho e de obtenção de renda, com o crescimento do emprego formal e das remunerações oferecidas em alguns setores, configurando uma certa tendência de maior integração social. Mas o esgotamento da "industrialização por substituição de importações" também mudou a realidade econômica da RMS. O avanço da crise nos anos 90, o ajuste e as transformações dele decorrentes afetaram negativamente a economia regional e interromperam a frágil estruturação do mercado de trabalho iniciada nas décadas anteriores, reforçando características da estrutura ocupacional associadas - nos anos 1960-70 - ao atraso da região que, supostamente, seriam superadas com o avanço da industrialização: o desemprego estrutural, a informalidade e a tendência à queda dos rendimentos reais dos trabalhadores.

\section{O panorama dos anos recentes}

As consequiências da reestruturação produtiva sobre Salvador e sua região metropolitana não diferem substancialmente das observadas em outros grandes centros brasileiros, com a sua dimensão e repercussões adversas ampliadas por condições e especificidades locais.

A Tabela I, baseada em dados da Pesquisa Nacional por Amostragem de Domicílios (IBGE), revela as mudanças fundamentais ocorridas na distribuição da ocupação nas principais regiões metropolitanas brasileiras entre 1993 e 1999. 


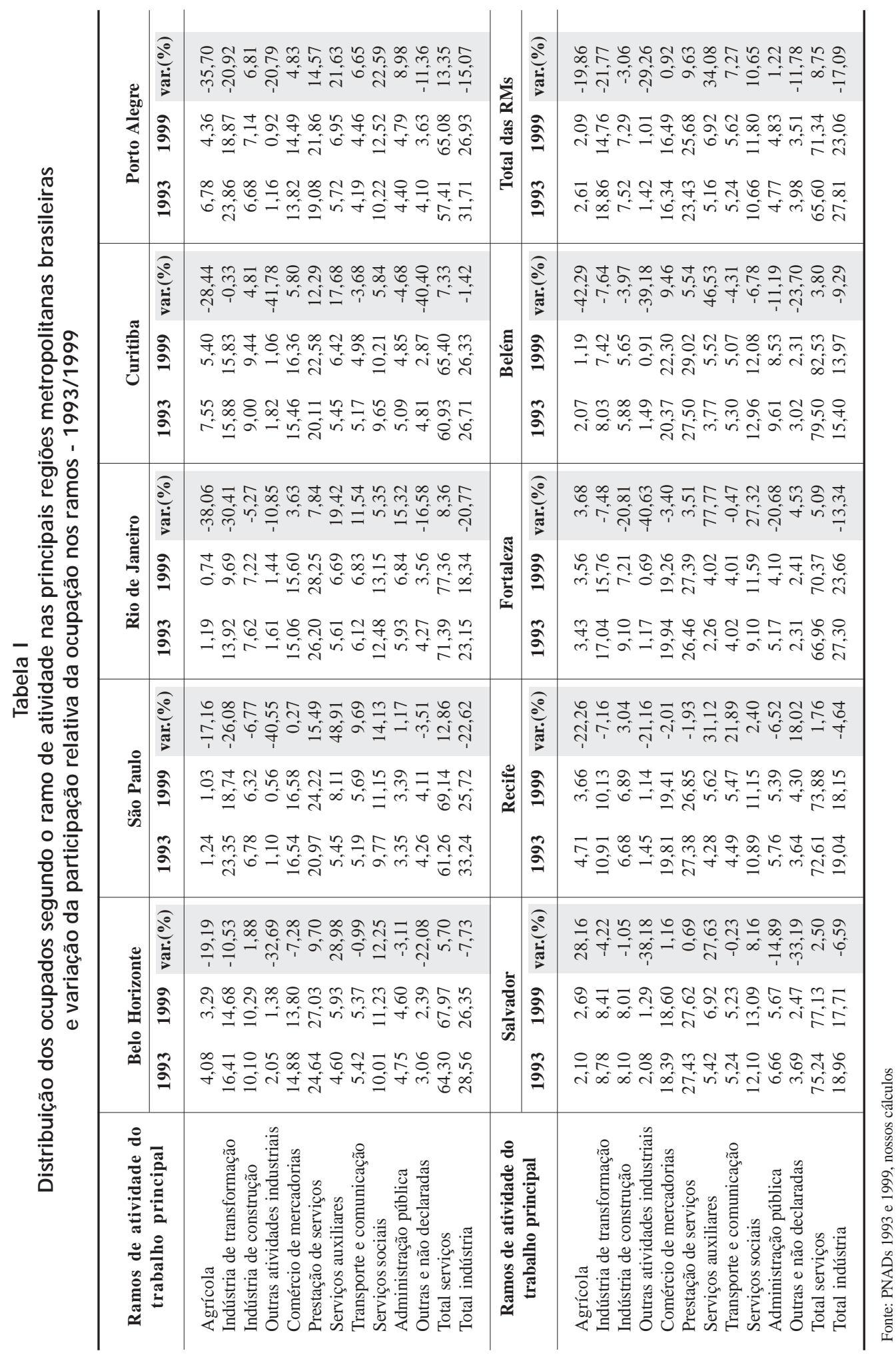


A constatação mais relevante é a desindustrialização absoluta e/ ou relativa da ocupação na maior parte das regiões, especialmente naquelas que concentravam o grosso da indústria brasileira: São Paulo, Rio de Janeiro, Belo Horizonte e Porto Alegre. A tabela II mostra como a ocupação na indústria de transformação cai absolutamente nestas regiões, com exceção de Belo Horizonte, que apresenta variação positiva, ainda que medíocre. Nota-se, ao mesmo tempo, o crescimento da ocupação industrial sobretudo em Curitiba, mas também em Salvador e, em menor grau, em Fortaleza. Nestas três regiões periféricas, a desindustrialização é apenas relativa; a ocupação industrial cresce, mas avança menos do que a ocupação nos serviços. Isto porque, se fatores como a acelerada inovação tecnológica destroem empregos na indústria, ocorre, também, uma migração do capital, que abandona os grandes centros saturados, atraído pela combinação de incentivos fiscais, ausência de sindicatos fortes e outras condições da periferia. Este é o caso, fundamentalmente, da região metropolitana de Curitiba, que tem abrigado parcela considerável dos novos investimentos automobilísticos no país.

Tabela II

Crescimento do número de ocupados segundo o ramo de atividade entre 1993 e 1999 em regiões metropolitanas selecionadas - (\%)

\begin{tabular}{|c|c|c|c|c|c|c|c|c|c|c|}
\hline $\begin{array}{l}\text { Ramo de atividade do } \\
\text { trabalho principal }\end{array}$ & $\begin{array}{c}\text { Belo } \\
\text { Horizonte }\end{array}$ & $\begin{array}{c}\text { São } \\
\text { Paulo }\end{array}$ & $\begin{array}{l}\text { Rio de } \\
\text { Janeiro }\end{array}$ & Curitiba & $\begin{array}{l}\text { Porto } \\
\text { Alegre }\end{array}$ & Salvador & Recife & Fortaleza & Belém & $\begin{array}{c}\text { Total das } \\
\text { RMs }\end{array}$ \\
\hline Agrícola & $-6,55$ & $-12,50$ & $-36,63$ & $-6,84$ & $-32,19$ & 49,30 & $-14,30$ & 13,38 & $-42,05$ & $-13,35$ \\
\hline Indústria de Transformação & 3,46 & $-21,92$ & $-28,81$ & 29,76 & $-16,61$ & 11,57 & 2,34 & 5,64 & $-7,26$ & $-15,41$ \\
\hline Indústria de Construção & 17,82 & $-1,53$ & $-3,09$ & 36,45 & 12,64 & 15,27 & 13,59 & $-9,58$ & $-3,57$ & 4,82 \\
\hline Outras atividades industriais & 22,16 & $-37,21$ & $-8,80$ & $-24,20$ & $-16,46$ & $-27,98$ & $-13,08$ & $-32,22$ & $-38,93$ & $-23,51$ \\
\hline Comércio de mercadorias & 7,23 & 5,92 & 6,02 & 37,75 & 10,55 & 17,85 & 8,03 & 10,29 & 9,91 & 9,12 \\
\hline Prestação de serviços & 26,86 & 21,98 & 10,32 & 46,20 & 20,82 & 17,29 & 8,11 & 18,19 & 5,98 & 18,54 \\
\hline Serviços auxiliares & 49,16 & 57,29 & 22,17 & 53,21 & 28,26 & 48,68 & 44,64 & 102,97 & 47,13 & 44,98 \\
\hline Transporte e comunicação & 14,50 & 15,86 & 14,11 & 25,40 & 12,47 & 16,23 & 34,37 & 13,64 & $-3,92$ & 15,99 \\
\hline Serviços sociais & 29,81 & 20,55 & 7,77 & 37,79 & 29,27 & 26,00 & 12,88 & 45,38 & $-6,40$ & 19,65 \\
\hline Administração pública & 12,04 & 6,87 & 17,98 & 24,10 & 14,93 & $-0,86$ & 3,05 & $-9,43$ & $-10,83$ & 9,45 \\
\hline Outras e não declaradas & $-9,89$ & 1,92 & $-14,66$ & $-22,40$ & $-6,53$ & $-22,17$ & 30,11 & 19,35 & $-23,39$ & $-4,61$ \\
\hline Total serviços & 16,68 & 11,46 & 4,61 & 29,51 & 11,57 & 13,82 & 6,82 & 15,99 & 0,41 & 10,86 \\
\hline TOTAL & 15,64 & 5,63 & 2,30 & 30,19 & 5,46 & 16,49 & 10,24 & 14,18 & 0,41 & 8,13 \\
\hline
\end{tabular}

O segundo fenômeno importante observado nas Tabelas I e II é a expansão dos novos serviços. A PNAD mostra o que dados da PED confirmarão adiante: nas regiões metropolitanas brasileiras, os postos de trabalho têm crescido sobretudo nos "serviços auxiliares" e nos "serviços sociais". A primeira categoria engloba, nos termos da PNAD, os serviços que apóiam outras atividades econômicas (vale dizer, empresariais de consumo intermediário) e os técnico-profissionais. A segunda corresponde aos serviços de saúde e educação. 
A Tabela III apresenta o "quociente de localização" (QL) dos diversos setores das economias metropolitanas brasileiras, ainda segundo a distribuição da ocupação registrada pela PNAD. Este quociente, como se sabe, ajuda a perceber o grau de especialização de uma determinada região em um determinado ramo de atividade. Os QLs registrados pela Tabela III identificam quatro regiões metropolitanas "especializadas" em atividades industriais: São Paulo, Porto Alegre, Curitiba e Belo Horizonte. As duas primeiras, com grande peso da indústria de transformação; as duas últimas, principalmente em razão do dinamismo recente da construção civil. No que diz respeito aos serviços, confirma-se: (a) o caráter de global city de São Paulo, em razão do peso dos seus serviços financeiros (incluídos em “ou-

Tabela III

Grau de especialização* da economia das principais regiões metropolitanas brasileiras segundo o ramo de atividade entre 1993 e 1999

\begin{tabular}{|c|c|c|c|c|c|c|c|c|c|c|}
\hline \multirow{2}{*}{$\begin{array}{l}\text { Ramos de atividade do } \\
\text { trabalho principal }\end{array}$} & \multicolumn{2}{|c|}{ Belo Horizonte } & \multicolumn{2}{|c|}{ São Paulo } & \multicolumn{2}{|c|}{ Rio de Janeiro } & \multicolumn{2}{|c|}{ Curitiba } & \multicolumn{2}{|c|}{ Porto Alegre } \\
\hline & 1993 & 1999 & 1993 & 1999 & 1993 & 1999 & 1993 & 1999 & 1993 & 1999 \\
\hline Agrícola & 1,56 & 1,57 & 0,48 & 0,49 & 0,46 & 0,35 & 2,89 & 2,58 & 2,60 & 2,08 \\
\hline Indústria de Transformação & 0,87 & 0,99 & 1,34 & 1,27 & 0,74 & 0,66 & 0,84 & 1,07 & 1,27 & 1,28 \\
\hline Indústria de Construção & 1,34 & 1,41 & 0,90 & 0,87 & 1,01 & 0,99 & 1,20 & 1,29 & 0,89 & 0,98 \\
\hline Outras atividades industriais** & 1,44 & 1,37 & 0,77 & 0,65 & 1,13 & 1,43 & 1,28 & 1,05 & 0,82 & 0,92 \\
\hline Comércio de mercadorias & 0,91 & 0,84 & 1,01 & 1,01 & 0,92 & 0,95 & 0,95 & 0,99 & 0,85 & 0,88 \\
\hline Prestação de serviços & 1,05 & 1,05 & 0,90 & 0,94 & 1,12 & 1,10 & 0,86 & 0,88 & 0,81 & 0,85 \\
\hline Serviços auxiliares & 0,89 & 0,86 & 1,05 & 1,17 & 1,09 & 0,97 & 1,06 & 0,93 & 1,11 & 1,00 \\
\hline Transporte e comunicação & 1,03 & 0,95 & 0,99 & 1,01 & 1,17 & 1,21 & 0,99 & 0,89 & 0,80 & 0,79 \\
\hline Serviços sociais & 0,94 & 0,95 & 0,92 & 0,95 & 1,17 & 1,11 & 0,90 & 0,87 & 0,96 & 1,06 \\
\hline Administração pública & 1,00 & 0,95 & 0,70 & 0,70 & 1,24 & 1,42 & 1,07 & 1,00 & 0,92 & 0,99 \\
\hline Outras e não declaradas & 0,77 & 0,68 & 1,07 & 1,17 & 1,07 & 1,01 & 1,21 & 0,82 & 1,03 & 1,03 \\
\hline Total serviços & 0,96 & 0,94 & 0,91 & 0,96 & 1,07 & 1,07 & 0,91 & 0,90 & 0,86 & 0,90 \\
\hline Total indústria & 1,08 & 1,20 & 1,26 & 1,17 & 0,88 & 0,83 & 1,01 & 1,19 & 1,20 & 1,22 \\
\hline \multirow{2}{*}{$\begin{array}{l}\text { Ramos de atividade do } \\
\text { trabalho principal }\end{array}$} & \multicolumn{2}{|c|}{ Salvador } & \multicolumn{2}{|c|}{ Recife } & \multicolumn{2}{|c|}{ Fortaleza } & \multicolumn{2}{|c|}{ Belém } & \multicolumn{2}{|c|}{ Total das RMs } \\
\hline & 1993 & 1999 & 1993 & 1999 & 1993 & 1999 & 1993 & 1999 & 1993 & 1999 \\
\hline Agrícola & 0,80 & 1,29 & 1,80 & 1,75 & 1,31 & 1,70 & 0,79 & 0,57 & 1,00 & 1,00 \\
\hline Indústria de Transformação & 0,47 & 0,57 & 0,58 & 0,69 & 0,90 & 1,07 & 0,43 & 0,50 & 1,00 & 1,00 \\
\hline Indústria de Construção & 1,08 & 1,10 & 0,89 & 0,94 & 1,21 & 0,99 & 0,78 & 0,77 & 1,00 & 1,00 \\
\hline Outras atividades industriais** & 1,46 & 1,28 & 1,02 & 1,13 & 0,82 & 0,69 & 1,05 & 0,90 & 1,00 & 1,00 \\
\hline Comércio de mercadorias & 1,13 & 1,13 & 1,21 & 1,18 & 1,22 & 1,17 & 1,25 & 1,35 & 1,00 & 1,00 \\
\hline Prestação de serviços & 1,17 & 1,08 & 1,17 & 1,05 & 1,13 & 1,07 & 1,17 & 1,13 & 1,00 & 1,00 \\
\hline Serviços auxiliares & 1,05 & 1,00 & 0,83 & 0,81 & 0,44 & 0,58 & 0,73 & 0,80 & 1,00 & 1,00 \\
\hline Transporte e comunicação & 1,00 & 0,93 & 0,86 & 0,97 & 0,77 & 0,71 & 1,01 & 0,90 & 1,00 & 1,00 \\
\hline Serviços sociais & 1,14 & 1,11 & 1,02 & 0,95 & 0,85 & 0,98 & 1,22 & 1,02 & 1,00 & 1,00 \\
\hline Administração pública & 1,40 & 1,17 & 1,21 & 1,12 & 1,08 & 0,85 & 2,01 & 1,77 & 1,00 & 1,00 \\
\hline Outras e não declaradas & 0,93 & 0,70 & 0,91 & 1,22 & 0,58 & 0,69 & 0,76 & 0,66 & 1,00 & 1,00 \\
\hline Total serviços & 1,15 & 1,08 & 1,10 & 1,04 & 1,02 & 0,98 & 1,21 & 1,15 & 1,00 & 1,00 \\
\hline Total indústria & 0,64 & 0,74 & 0,67 & 0,77 & 0,99 & 1,04 & 0,53 & 0,59 & 1,00 & 1,00 \\
\hline
\end{tabular}

*O grau de especialização aqui equivale ao "QL", ou quociente de localização. O QL é uma técnica para medir a especialização de uma região numa determinada atividade econômica. Na tabela acima, um $\mathrm{QL}=1$ significa que uma região metropolitana tem a mesma porcentagem de ocupados numa determinada atividade que o conjunto das regiões metropolitanas; um QL $>1$, significa que ela é mais "especializada" na atividade em questão do que esse mesmo conjunto; inversamente, um QL $<1$ implica que a região tem proporcionalmente menos ocupados em uma determinada atividade. Assim, por exemplo, na mesma tabela, São Paulo e Porto Alegre aparecem como regiões metropolitanas fortemente industrializadas (QLs=1,27 e 1,28, respectivamente, em 1999). Ao mesmo tempo, Salvador e Belém têm, relativamente, muito pouca atividade industrial ( $Q L s=0,57$ e 0,50$)$.

** As outras atividades industriais são compostas de extração mineral e serviços de utilidade pública. Dado o maior peso desta última categoria, foram incluídas no total de serviços.

Fontes: PNADs 1993 e 1999 
tras e não declaradas") e do desenvolvimento de seus serviços empresariais; (b)a terciarização acelerada do Rio de Janeiro, com especialização marcada em serviços de utilidade pública, prestação de serviços, transporte e comunicação, serviços sociais e, particularmente, administração pública; (c) o caráter não-industrial das regiões metropolitanas de Salvador, Recife e Belém; o peso da administração pública e do comércio e, por conseguinte, sua importância para a geração de ocupações nestas regiões; e (d) a posição intermediária de Fortaleza, que combina alguma presença de ocupação industrial e um menor peso da administração pública com uma importância ainda grande do comércio e pouco desenvolvimento dos serviços de consumo intermediário.

Quanto a Salvador, a Tabela III demonstra, ainda que indiretamente, que esta metrópole de grande porte se situa num estado com poucas cidades de porte médio, onde o chamado "efeito-capital" se desenvolve plenamente. É o que provavelmente indica o grau de especialização mais elevado em serviços de utilidade pública, comércio, serviços sociais e administração pública.

Os dados mais recentes da PNAD comprovam um fenômeno que já se começava a perceber no final da década de 80: a terciarização que se processou nas metrópoles brasileiras nas duas últimas décadas não se confunde com a terciarização "espúria" identificada nos anos 60 e 70 (ver, por exemplo, Andrade, 1995). As análises dos anos 90, porém, ainda estavam fortemente influenciadas pelos críticos do "pós-industrialismo" à la Daniel Bell (1973), dos quais os representantes típicos foram Cohen e Zysman (1987). Elas se resumiam a notar uma expansão dos serviços "produtivos", "complementares", "modernos”, que seria subordinada à expansão industrial, num quadro de uma nova dinâmica da indústria (considerada como o "motor" da transformação). A questão atual é ir além deste tipo de visão e reconhecer que muitos segmentos dos serviços têm hoje uma dinâmica própria no plano regional, crescendo independentemente da performance imediata da indústria, como ocorre, por exemplo, com o turismo, a educação e a saúde. Entre outros fatores porque grandes metrópoles constituem grandes mercados, oferecendo condições para o crescimento da chamada "economia da urbanização”: pequenas indústrias de alimentos e confecções, comércio varejista, prestação de serviços, etc. Além disso, elas podem oferecer maiores externalidades - economias de aglomeração - às empresas que se expandem em escala nacional ou internacional, na medida em que concentram os segmentos produtivos destinados ao atendimento ao setor empresarial.

Concluindo esta breve análise comparativa das principais economias metropolitanas brasileiras, a Tabela IV mostra claramente como a "guerra fiscal", associada à migração espontânea do capital industrial footloose, tem levado ao incremento da participação de algumas metrópoles periféricas no conjunto da ocupação industrial (indústria de transformação). Nessa guerra, São Paulo e Rio de Janeiro vêm perdendo. Ganham Curitiba, Belo Horizonte e umas poucas capitais nordestinas. Essa tabela confirma ainda que não são estas últimas cidades que mais se beneficiam do relativo esvaziamento industrial de São Paulo (onde crescem os serviços empresariais e financeiros) e do Rio de Janeiro 
(que continua concentrando serviços de utilidade pública e administração pública). As regiões metropolitanas mais dinâmicas estão na periferia próxima do pólo dominante nacional: Curitiba e Belo Horizonte.

Tabela IV

Distribuição das ocupações entre as principais regiões metropolitanas brasileiras segundo o ramo de atividade entre 1993 e 1999

\begin{tabular}{|c|c|c|c|c|c|c|c|c|c|c|}
\hline \multirow{2}{*}{$\begin{array}{l}\text { Ramos de atividade do } \\
\text { trabalho principal }\end{array}$} & \multicolumn{2}{|c|}{ Belo Horizonte } & \multicolumn{2}{|c|}{ São Paulo } & \multicolumn{2}{|c|}{ Rio de Janeiro } & \multicolumn{2}{|c|}{ Curitiba } & \multicolumn{2}{|c|}{ Porto Alegre } \\
\hline & 1993 & 1999 & 1993 & 1999 & 1993 & 1999 & 1993 & 1999 & 1993 & 1999 \\
\hline Agrícola & 13,11 & 14,14 & 17,67 & 17,84 & 10,37 & 7,58 & 14,33 & 15,40 & 20,98 & 16,41 \\
\hline Indústria de Transformação & 7,31 & 8,94 & 49,98 & 46,13 & 16,77 & 14,12 & 4,17 & 6,40 & 10,22 & 10,08 \\
\hline Indústria de Construção & 11,28 & 12,68 & 33,51 & 31,48 & 23,03 & 21,29 & 5,93 & 7,72 & 7,18 & 7,71 \\
\hline Outras atividades industriais & 12,09 & 12,30 & 28,77 & 23,62 & 25,74 & 30,69 & 6,33 & 6,28 & 6,61 & 7,22 \\
\hline Comércio de mercadorias & 7,65 & 7,52 & 37,63 & 36,53 & 20,95 & 20,35 & 4,69 & 5,92 & 6,83 & 6,92 \\
\hline Prestação de serviços & 8,84 & 9,46 & 33,29 & 34,26 & 25,42 & 23,66 & 4,25 & 5,25 & 6,58 & 6,71 \\
\hline Serviços auxiliares & 7,49 & 7,70 & 39,21 & 42,54 & 24,67 & 20,79 & 5,23 & 5,53 & 8,95 & 7,91 \\
\hline Transporte e comunicação & 8,69 & 8,58 & 36,80 & 36,76 & 26,54 & 26,11 & 4,89 & 5,29 & 6,45 & 6,26 \\
\hline Serviços sociais & 7,89 & 8,56 & 34,07 & 34,32 & 26,62 & 23,98 & 4,49 & 5,17 & 7,74 & 8,37 \\
\hline Administração pública & 8,36 & 8,56 & 26,10 & 25,49 & 28,26 & 30,46 & 5,29 & 6,00 & 7,45 & 7,82 \\
\hline Outras e não declaradas & 6,46 & 6,10 & 39,80 & 42,53 & 24,35 & 21,78 & 5,99 & 4,87 & 8,32 & 8,15 \\
\hline \multirow{2}{*}{$\begin{array}{l}\text { Ramos de atividade do } \\
\text { trabalho principal }\end{array}$} & \multicolumn{2}{|c|}{ Salvador } & \multicolumn{2}{|c|}{ Recife } & \multicolumn{2}{|c|}{ Fortaleza } & \multicolumn{2}{|c|}{ Belém } & \multicolumn{2}{|c|}{ Total das RMs } \\
\hline & 1993 & 1999 & 1993 & 1999 & 1993 & 1999 & 1993 & 1999 & 1993 & 1999 \\
\hline Agrícola & 4,45 & 7,66 & 10,68 & 10,56 & 6,83 & 9,33 & 1,59 & 1,07 & 1,00 & 1,00 \\
\hline Indústria de Transformação & 2,57 & 3,39 & 3,42 & 4,14 & 4,69 & 5,86 & 0,86 & 0,94 & 1,00 & 1,00 \\
\hline Indústria de Construção & 5,95 & 6,54 & 5,26 & 5,70 & 6,29 & 5,42 & 1,57 & 1,45 & 1,00 & 1,00 \\
\hline Outras atividades industriais & 8,07 & 7,60 & 6,01 & 6,83 & 4,26 & 3,78 & 2,11 & 1,68 & 1,00 & 1,00 \\
\hline Comércio de mercadorias & 6,22 & 6,71 & 7,17 & 7,10 & 6,34 & 6,41 & 2,51 & 2,53 & 1,00 & 1,00 \\
\hline Prestação de serviços & 6,47 & 6,40 & 6,92 & 6,31 & 5,87 & 5,85 & 2,36 & 2,11 & 1,00 & 1,00 \\
\hline Serviços auxiliares & 5,80 & 5,95 & 4,91 & 4,89 & 2,28 & 3,19 & 1,47 & 1,49 & 1,00 & 1,00 \\
\hline Transporte e comunicação & 5,53 & 5,54 & 5,07 & 5,87 & 3,99 & 3,91 & 2,03 & 1,68 & 1,00 & 1,00 \\
\hline Serviços sociais & 6,27 & 6,60 & 6,05 & 5,70 & 4,44 & 5,39 & 2,44 & 1,91 & 1,00 & 1,00 \\
\hline Administração pública & 7,71 & 6,98 & 7,15 & 6,73 & 5,63 & 4,66 & 4,05 & 3,30 & 1,00 & 1,00 \\
\hline Outras e não declaradas & 5,12 & 4,18 & 5,41 & 7,38 & 3,02 & 3,77 & 1,53 & 1,23 & 1,00 & 1,00 \\
\hline
\end{tabular}

Fontes: PNADs 1993 e 1999

Sendo assim, como as transformações da atualidade estariam repercutindo sobre as demais metrópoles brasileiras e, especialmente, sobre aquelas situadas nas regiões menos desenvolvidas do país, fora do eixo urbano do Centro-Sul? Como estariam evoluindo a estrutura ocupacional e social dessas cidades, suas marcantes desigualdades e as condições de vida das suas populações?

Conforme já assinalado, no caso de Salvador e de sua região metropolitana, o impacto da reestruturação produtiva não difere radicalmente do que tem sido observado em outros grandes centros brasileiros, embora alguns fenômenos e problemas venham sendo agravados por condições e especificidades locais. Utilizando a tipologia sócio-ocupacional e dados elaborados pelo projeto Metrópoles, Desigualdades Sócio-Espaciais e Governança Urbana ${ }^{1}$, verifica-se

${ }^{1}$ Agradecemos aos coordenadores do Projeto a elaboração e a cessão de dados com essa tipologia para Salvador. 
que não houve uma redefinição mais ampla da estrutura sócio-ocupacional e, muito menos, um processo de dualização social. A elite dirigente se ampliou, com o aumento da participação dos empresários e dos profissionais liberais. As classes médias mantiveram a sua participação relativa, embora empobrecidas e com reconfigurações. O operariado industrial se reduziu e o proletariado terciário cresceu significativamente, enquanto que a dimensão do sub-proletariado (marca histórica da região) não apenas continuou mais elevada do que em outras metrópoles brasileiras como se ampliou, ainda mais.

Tabela V

Evolução da composição da ocupação na RMS - 1988/1989 e 1996/1999

\begin{tabular}{|c|c|c|c|}
\hline Setores e subsetores & $1987 / 1988$ & $1996 / 1999$ & Variação \% \\
\hline Agropecuária e extração vegetal & 2,3 & 1,4 & $-38,4$ \\
\hline Indústria de transformação & 12,2 & 8,2 & $-32,8$ \\
\hline Metalúrgica, mecânica, elétrica, transporte & 2,3 & 1,3 & $-43,7$ \\
\hline Têxtil, vestuário e calçados & 1,1 & 0,8 & $-22,9$ \\
\hline Alimentos & 1,4 & 1,4 & 4,3 \\
\hline Mobiliário e outros produtos de madeira & 0,6 & 0,6 & $-3,5$ \\
\hline Complexo químico e petroquímico* & 3,8 & 2,3 & $-41,2$ \\
\hline Gráfica & 0,6 & 0,5 & $-9,0$ \\
\hline Materiais de construção & 0,7 & 0,3 & 52,4 \\
\hline Artesanato & 0,3 & 0,5 & 53,2 \\
\hline Outras indústrias de transformação & 1,5 & 0,6 & $-63,3$ \\
\hline Construção civil & 7,5 & 5,4 & $-27,8$ \\
\hline Comércio de mercadorias & 18,7 & 17,0 & $-8,8$ \\
\hline Serviços & 58,1 & 67,5 & 16,2 \\
\hline Adm. pública, polícia e forças armadas & 7,7 & 7,3 & $-6,0$ \\
\hline Serviço de utilidade pública & 1,8 & 1,2 & $-33,3$ \\
\hline Transporte e armazenagem & 4,1 & 4,3 & 5,4 \\
\hline Serviços creditíceos e financeiros & 2,3 & 1,8 & $-24,5$ \\
\hline Administração e comércio de imóveis & 0,3 & 1,4 & 416,8 \\
\hline Serviços especializados & 1,7 & 3,5 & 113,0 \\
\hline Serviços auxiliares & 2,0 & 4,0 & 99,2 \\
\hline Serviços de limpeza, vigilância e oficinas & 1,8 & 5,2 & 191,6 \\
\hline Oficinas de reparação mecânica & 1,9 & 2,2 & 11,6 \\
\hline Serviços de comunicação e diversão** & 1,0 & 2,2 & 122,8 \\
\hline Serviços de alimentação & 5,4 & 6,2 & 14,0 \\
\hline Hotéis, pensões e alojamentos & ND & 0,5 & - \\
\hline Educação & 5,7 & 7,4 & 28,4 \\
\hline Saúde & 3,5 & 4,4 & 27,1 \\
\hline Serviços comunitários & 0,9 & 1,2 & 32,9 \\
\hline Serviços pessoais & 5,9 & 1,6 & $-73,1$ \\
\hline Serviços domésticos & 9,3 & 10,5 & 12,9 \\
\hline Outros serviços & 2,7 & 2,6 & $-5,7$ \\
\hline Outras atividades & 1,2 & 0,4 & $-65,6$ \\
\hline TOTAL & 100 & 100 & - \\
\hline
\end{tabular}

* Inclui: plásticos, farmacêutica e artefatos de borracha

** Inclui: rádio e televisão

Fonte: PED/RMS-UFBa/SEI/SEPLANTEC/SEADE/DIEESE (Agregação das amostras de 1987/88 e 1996/99). 
Além disso, também na capital baiana vem se registrando uma melhoria do nível educacional da população ocupada, a precarização das relações de trabalho, um aumento significativo do emprego nas atividades do setor terciário e um empobrecimento expressivo da quase totalidade dos trabalhadores.

Com base em informações da $\mathrm{PED}^{2}$ pode-se analisar mais detalhadamente esses fenômenos, como a dinâmica da ocupação por setores e sub-setores de atividade dos anos 80 para os anos 90, apresentada na Tabela V.

Nesta tabela fica patente a redução dos postos em setores que experimentaram uma intensa renovação tecnológica e organizacional ou foram objeto de privatizações, como a indústria petroquímica e outros ramos da indústria de transformação, os serviços creditícios e financeiros e os serviços de utilidade pública. Dificuldades de financiamento da construção residencial e a restrição dos investimentos em obras públicas certamente contribuíram para reduzir o peso da ocupação na construção civil. Surpreendentemente, a evolução da ocupação também foi negativa no caso dos serviços pessoais. Não se sabe até que ponto esse fenômeno, que contraria as expectativas e formulações de vários autores, representa ou não uma especificidade da região metropolitana de Salvador. Como explicação para o mesmo, levanta-se a hipótese da aceleração do progresso técnico e da concentração em estabelecimentos modernos de alguns desses serviços, com a expansão de redes e franquias, paralelamente ao crescimento do auto-serviço na área de higiene pessoal (principal segmento do setor), tanto em decorrência do seu encarecimento após o Plano Real como da mudança de certos hábitos entre a população.

A redução da ocupação nos setores assinalados foi concomitante à sua expansão em outros segmentos dos serviços. Mais precisamente: (a) na administração de imóveis, notadamente com o incremento das ocupações de condomínio e a necessidade de uma maior segurança em habitações coletivas; (b) na área dos serviços especializados, tanto em decorrência do crescimento da terceirização como da demanda de novos serviços qualificados (consultoria, contabilidade, informática e outros); (c) nos serviços auxiliares, ou seja, em uma constelação de ocupações relacionadas com o trabalho de escritórios e de firmas comerciais; (d) nas atividades de vigilância, limpeza e reparação ou manutenção não mecânicas, que foram objetos de uma intensa terceirização; (e) nos serviços de comunicação e diversão e (f) nas áreas sociais da educação, saúde e serviços comunitários.

Esta terciarização nova da economia da RMS se faz num contexto de "reengenharia", "downsizing" e "flexibilização" crescente do trabalho. Conforme ressaltam Borges e Filgueiras (1995), a redução de quadro de pessoal atingiu todos os setores de atividade, com o avanço do processo de terceirização, a precarização dos vínculos, a queda dos rendimentos e uma deterioração das condições de trabalho. Apenas na administração pública, onde os empregados estão protegidos pelo estatuto da estabilidade, o ajuste vem se dando por uma drástica redução dos salários
2 Trata-se da Pesquisa Emprego e Desemprego, efetuada em algumas metrópoles brasileiras, que na Região Metropolitana de Salvador é realizada atualmente pela Faculdade de Ciências Econômicas da Universidade Federal da Bahia, em convênio com o Governo do Estado da Bahia (através da SEPLANTEC), o DIEESE e a Fundação SEADE de São Paulo. 
reais e pelo uso crescente do trabalho de "estagiários". Registra-se igualmente, em Salvador, um fenômeno comum em outras regiões do Brasil e do mundo, a substituição de trabalhadores de mais baixa escolarização por outros mais escolarizados para ocupar os mesmos postos de trabalho (cf. Azevedo, 2001).

A precarização dos vínculos pode ser observada através da Tabela VI, cujos dados deixam patente a queda do emprego protegido e dos trabalhadores familiares, paralelamente a um grande aumento dos assalariados sem carteira assinada e dos ocupados como empregadores, donos de negócios familiares e profissionais liberais.

Tabela VI

Posição na ocupação e desemprego na RMS - 1987/1988 e 1996/1999

\begin{tabular}{l|r|r|r}
\hline \multicolumn{1}{c|}{ Posição na ocupação / desemprego } & $\mathbf{1 9 8 7 / 1 9 8 8}$ & $\mathbf{1 9 9 6 / 1 9 9 9}$ & Variação \% \\
\hline Assalariados setor privado com carteira & 32,4 & 30,3 & $-6,0$ \\
Assalariados setor privado sem carteira & 8,3 & 11,0 & 33,0 \\
Assalariados setor público & 15,6 & 16,0 & 3,0 \\
Autônomos & 24,6 & 24,2 & $-2,0$ \\
Empregadores, profissionais liberais e & & & \\
donos de negócios familiares & 3,2 & 5,1 & 59,0 \\
Trabalhadores domésticos & 10,8 & 10,5 & $-3,0$ \\
Trabalhadores familiares & 2,7 & 2,0 & $-26,0$ \\
Desemprego aberto & 8,9 & 13,8 & 55,0 \\
Desemprego oculto & 7,0 & 10,5 & 50,0 \\
Desemprego total & 15,8 & 24,3 & 54,0 \\
\end{tabular}

Fonte: PED/RMS-UFBa/SEI/SEPLANTEC/SEADE/DIEESE (Agregação das amostras de 1987/88 e 1996/99).

O crescimento da informalidade (conceituada aqui como o trabalho não protegido, abrangendo os assalariados sem carteira assinada e os autônomos e empregadores que não contribuem para a previdência social), decorre das mudanças e da precarização das relações de trabalho, mas também está associada a expansão de certas demandas e ocupações.

Este fenômeno vem se traduzindo não apenas no crescimento da informalidade como da sua própria diferenciação. Segundo a amostra da PED/RMS para 1996-98, 43\% dos ocupados de Salvador (correspondendo a cerca de 380 mil trabalhadores) encontravam-se na informalidade. $78 \%$

${ }^{3} \mathrm{Na}$ amostra PED/RMS 1996-1998, o valor da mediana da distribuição dos rendimentos era de R\$245,00 mensais, o que representava cerca de U\$250.00, antes da desvalorização do Real. dos trabalhadores nessa condição com declaração de renda tinham ganhos inferiores à mediana dos trabalhadores locais ${ }^{3}$, podendo ser considerados como "excluídos". Contudo, apesar da precariedade da sua inserção ocupacional, entre 1987-1988 e 1996-1998 uma parcela desses trabalhadores obteve uma significativa melhoria de renda.

Entre as explicações para esse fenômeno vale ressaltar que em Salvador e em outras metrópoles, a informalidade é vivida em diferentes 
situações. De um lado, ela constitui uma condição temporária, própria dos primeiros contatos com o mercado de trabalho, que diz respeito sobretudo aos jovens de até 24 anos e pode ser revertida com o tempo. Para muitos trabalhadores, entretanto, ela é uma condição permanente, que configura uma nova forma de inserção no mercado de trabalho, estratégia de sobrevivência ou até de sucesso, nesta época de reestruturação produtiva, flexibilização das relações de trabalho e elevado desemprego estrutural.

O emprego formal predomina nas atividades de administração e utilidade pública, nos serviços creditícios e nas áreas de saúde e de educação. Já a informalidade persiste concentrada no comércio, serviços domésticos, construção civil e serviços de alimentação, assim como nos setores de limpeza e oficinas mecânicas, em ocupações de menor qualificação e renda, como os trabalhadores de serventia (em domicílios ou empresas), os vendedores, comerciários, trabalhadores braçais, trabalhadores da construção civil, lavadeiras, passadeiras, costureiras e trabalhadores de limpeza e conservação.

Contudo, a terceirização, a ampliação da demanda de serviços especializados e de oportunidades para pequenos negócios tem levado a uma diferenciação desses trabalhadores, com o crescimento de uma elite (cerca de $11 \%$ ) que poderia ser chamada de "informais integrados", associada ao processo atual de reconfiguração das classes médias (cf. Almeida \& Azevedo, 1999b).

Trata-se, predominantemente, de homens brancos, maduros, com instrução de segundo e terceiro grau, autônomos ou micro-empresários, que atuam principalmente na prestação de serviços auxiliares, serviços especializados ou de alimentação. Seu número também cresceu na indústria mas declinou na construção civil, com a crise desse ramo. Apesar da insegurança, da ausência de proteção social e de jornadas superiores a 48 horas semanais, este grupo foi o único a escapar do empobrecimento dos trabalhadores associado à reestruturação produtiva e ao ajuste em todo o Brasil, particularmente acentuado na Região Metropolitana de Salvador pelas características do mercado de trabalho local.

Como se observa na Tabela VII o rendimento médio do conjunto de ocupados nessa região metropolitana teve uma queda de $18,1 \%$, passando de $\mathrm{R} \$ 686,00$ em 1987-1988 para R \$ 562,00 em 1996-1998. Esta perda atingiu duramente os trabalhadores formais e, como seria de esperar, sobretudo os formais precarizados, que denominamos como "excluídos”. Já os trabalhadores informais tiveram um aumento de cerca de $20 \%$ na sua renda média em decorrência da mencionada diferenciação. A situação e as baixas remunerações dos informais "excluídos” praticamente não mudaram. Mas os "informais incluídos", como já foi visto, tiveram algum ganho em termos reais. Note-se ainda que os desvios padrão são bem maiores entre os trabalhadores formais e informais de maior renda, evidenciando uma diferenciação crescente no topo da pirâmide social. 
Tabela VII

Rendimento real dos ocupados em Salvador (em Reais, de agosto de 1998)

\begin{tabular}{c|r|r|r|r|r|r}
\hline \multirow{2}{*}{ Trabalhadores ocupados } & \multicolumn{2}{|c|}{ Freqüência relativa } & \multicolumn{2}{|c|}{ Renda média } & \multicolumn{2}{c}{ Desvio Padrão } \\
\cline { 2 - 7 } & $\mathbf{1 9 8 7 / 1 9 8 8}$ & $\mathbf{1 9 9 6 / 1 9 9 8}$ & $\mathbf{1 9 8 7 / 1 9 8 8}$ & $\mathbf{1 9 9 6 / 1 9 9 8}$ & $\mathbf{1 9 8 7 / 1 9 8 8}$ & $\mathbf{1 9 9 6 / 1 9 9 8}$ \\
\cline { 2 - 7 } Total de ocupados & 100,0 & 100,0 & 686 & 562 & 1254 & 829 \\
Trabalhadores formais & 64,3 & 59,9 & 923 & 728 & 1452 & 938 \\
Incluídos $^{*}$ & 42,5 & 38,6 & 1192 & 1034 & 1239 & 1050 \\
Excluídos $^{* *}$ & 21,7 & 21,3 & 215 & 173 & 55 & 51 \\
Trabalhadores informais & 35,7 & 40,1 & 261 & 314 & 576 & 543 \\
Incluídos $^{*}$ & 7,4 & 11,3 & 761 & 806 & 770 & 834 \\
Excluídos $^{* *}$ & 28,5 & 28,8 & 119 & 120 & 76 & 62 \\
\hline
\end{tabular}

* Exclusive os ocupados que não declararam ou não tiveram rendimento

* Trabalhadores protegidos mas com ganhos inferiores à mediana dos trabalhadores locais

Fonte: PED/RMS-UFBa/SEI/SEPLANTEC/SEADE/DIEESE

A deterioração dos rendimentos e das condições de subsistência da população da RMS podem ser melhor observadas, porém, quando se considera o rendimento familiar (Tabela VIII). Além da queda da renda média familiar, a distribuição das famílias nas classes de renda mensal familiar também mudou no intervalo estudado. A proporção de famílias que ganhavam acima de duas vezes o valor da mediana da distribuição individual de renda (cerca de 4 salários mínimos), passou de 48,5\% em 1987-1988 para 35,0\% em 1996-1998. Ao mesmo tempo, cresceu a proporção de famílias que ganhavam entre dois e quatro salários mínimos sugerindo que boa parte das famílias com maior renda tenha passado para esta faixa. A proporção de famílias na classe mais baixa de rendimento mensal familiar, também se eleva de $21,2 \%$ para $33 \%$ na década. Em suma, caiu significativamente a renda média familiar no período estudado.

Tabela VIII

Rendimento das famílias de Salvador - 1987/1988 e 1996/1998

\begin{tabular}{|c|c|c|c|c|c|c|}
\hline \multirow[t]{3}{*}{$\begin{array}{l}\text { Classes de rendimento } \\
\text { familiar mensal }\end{array}$} & \multicolumn{4}{|c|}{ Total de famílias } & \multicolumn{2}{|c|}{$\begin{array}{c}\text { Famílias chefiadas } \\
\text { por informais }\end{array}$} \\
\hline & \multicolumn{2}{|c|}{$1987 / 1988$} & \multicolumn{2}{|c|}{$1996 / 1998$} & $1987 / 1988$ & $1996 / 1998$ \\
\hline & $\begin{array}{c}\mathrm{R} \$ \\
(\text { média })^{1}\end{array}$ & i & $\begin{array}{c}\mathrm{R} \$ \\
(\text { média })^{1}\end{array}$ & i & $\begin{array}{c}\mathrm{R} \$ \\
(\text { média })^{1}\end{array}$ & $\underset{(\text { média })^{1}}{\mathrm{R} \$}$ \\
\hline Total & 1.194 & 100,0 & 919 & 100,0 & $1.227: 100,0$ & $928 \div 100,0$ \\
\hline Até 1 salário mínimo² & 149 & 21,2 & 94 & 33,0 & $146 \quad 20,6$ & $93 \quad 33,1$ \\
\hline Entre 1 e $2 \mathrm{SM}$ & 361 & I 21,2 & 192 & 12,3 & $359 \quad 21,1$ & 192 | 12,3 \\
\hline Mais de 2 SM a 2 medianas $^{3}$ & 542 & 9,3 & 383 & 19,7 & 540 & \begin{tabular}{l|l}
381 & 20,0
\end{tabular} \\
\hline Acima de 2 medianas & 2.095 & 48,5 & 1.702 & 35,0 & \begin{tabular}{l|l}
2.127 & 49,4
\end{tabular} & $1.727 \quad 34,6$ \\
\hline
\end{tabular}

${ }^{1}$ Todos os valores monetários em Reais de Agosto de 1998.

${ }^{2}$ Salário mínimo vigente e atualizado para agosto de 1998.

${ }^{3}$ Mediana da distribuição dos rendimentos (exclusive rendimentos zero) de cada uma das amostras. O valor da mediana (que divide as amostras ao meio) era de $\mathrm{R} \$ 312,00$ para 1987-88 e de $\mathrm{R} \$ 267,00$ para 1996-98, em valores de agosto de 1998. A pesquisa "Perfil sócio-econômico do trabalhador informal de Salvador" (UFBA/Prefeitura Municipal de Salvador), de onde esta tabela foi obtida, considerou como "pobres" as famílias que tinham renda total inferior a $\mathbf{2}$ vezes o valor da mediana da distribuição, que significava, na época, cerca de 4 salários mínimos.

Fonte: PED/RMS-UFBa/SEI/SEPLANTEC/SEADE/DIEESE. (Agregação das amostras de 1987/88 e 1996/99). Nossos cálculos.

Ainda que a redução dos rendimentos do trabalho e o aumento das desigualdades tenham um caráter nacional, em Salvador a pauperização 
vem se tornando bem mais ampla e extremada, em decorrência de um extraordinário desemprego.

Durante a década de 90, as taxas de desemprego aberto e oculto verificadas na RMS superaram, na maior parte do tempo, as encontradas nas outras regiões metropolitanas do país, como revelam tanto a Pesquisa Mensal de Emprego (PME), do IBGE como a Pesquisa de Emprego e Desemprego (PED). Como foi visto na Tabela VI, de 1987-88 a 1996-99, o crescimento do desemprego na Região Metropolitana de Salvador chegou a 55\% no conceito de desemprego aberto, $50 \%$ no de desemprego oculto e $54 \%$ em termos de desemprego total. Com a crise da desvalorização cambial de 1999, as freqüências encontradas pela PED superam os patamares de $14 \%$ e $25 \%$ no que tange respectivamente ao desemprego aberto e ao desemprego total.

Por que as taxas de desemprego em Salvador ficaram tão altas, superando as verificadas na maioria das outras regiões metropolitanas e capitais? Por que elas cresceram tanto no final dos anos 1990? Não foi especialmente por causa de um incremento acelerado da População Economicamente Ativa. Certo, houve imigração, crescimento da população em idade ativa e uma crescente entrada de mulheres na força de trabalho. Mas isso não diferenciou a RMS das outras regiões metropolitanas do país, que registraram taxas menores de desemprego. Também não se pode atribuir o problema à limitada "empregabilidade" do trabalhador da RMS, uma vez que, com a extensão da rede de ensino público, o grau de instrução da mão-de-obra (termômetro importante para a referida "empregabilidade") elevou-se consideravelmente da década de 80 para a década de 90.

Na verdade, a principal causa do desemprego em Salvador na última década foi a limitada criação de postos de trabalho na cidade e na sua região. Como em outras RMs, a redução absoluta de postos de trabalho registrada nesse período resultou da combinação de um processo estrutural - uma revolução tecnológica e organizacional num quadro de abertura da economia - com uma conjuntura determinada: a recessão da economia brasileira iniciada com a crise do Real.

Contudo, a RMS possui certas especificidades, como um maior peso dos serviços na sua economia do que em outras regiões metropolitanas. Nem todos os segmentos dos serviços apresentam dinamismo; muitos se caracterizam especialmente pela precariedade do trabalho e pela alta instabilidade da ocupação. E depois dos grandes investimentos do Pólo Petroquímico de Camaçari a economia da RMS apresentou taxas modestas de crescimento. A nova onda de investimentos footloose não alterou esta situação, até porque eles foram dirigidos em grande parte para cidades do interior da Bahia, em função de uma política deliberada de descentralização industrial bancada pelos últimos governos estaduais. O turismo - grande esperança - praticamente não cresceu entre 1994 e 1998, sobretudo por causa da sobrevalorização do câmbio, que afugentou o turista estrangeiro. Por diversos motivos, outros setores tradicionalmente importantes da economia local, como a construção civil e a indústria têxtil, passaram por sérias crises e demitiram. 
${ }^{4}$ Nos últimos anos os subúrbios ferroviários vêm se destacando também pela violência, com um número bastante elevado de mortes entre os jovens, provocados, inclusive, por grupos de extermínio que atuam na área.

${ }^{5}$ Como exemplo dessa política podem ser citadas a tentativa de atração da Kia (que desistiu do investimento depois de aproveitar a isenção de impostos para exportar seus automóveis) e, mais recentemente, a disputa de uma planta da Ford com o Rio Grande do Sul, que terminou sendo transferida para a Região Metropolitana de Salvador pelas maiores vantagens que lhe foram ofertadas. Esta planta acaba de ser inaugurada, não sendo possível, ainda, avaliar o seu impacto nem a relação custobenefício dos recursos e subsídios governamentais envolvidos nessa implantação.
Por outro lado, a desocupação, a pobreza, as desigualdades e as precárias condições de vida assinaladas são acentuadas pela segregação sócio-espacial constituída e consolidada no acelerado processo de crescimento e modernização da cidade. Apresentando uma grande riqueza de dados e mapas, Souza (2000) evidencia como mais da metade da população soteropolitana vive em moradias precárias, em áreas de ocupação informal e desordenada e deficientes condições de habitabilidade, sem infra-estrutura e serviços básicos. Enquanto os grandes equipamentos, o conforto ambiental, as vias de circulação, as oportunidades de trabalho, o comércio, os serviços e o lazer se concentram na área central e de ocupação mais antiga, no centro novo e na orla norte da cidade, é notória a sua carência no "miolo" e nos subúrbios ferroviários ${ }^{4}$, onde se aglomera a maioria da população e os segmentos pauperizados.

Tanto esse segregação sócio-espacial como os seus efeitos adversos tendem a se agravar. Como já foi visto, as novas orientações da economia brasileira e a ausência ou o encolhimento de iniciativas e políticas que pudessem atenuar os impactos espaciais e seletivos das atuais transformações deram origem a uma acirrada disputa por investimentos e empregos através da "guerra fiscal" e da oferta de vantagens crescentes aos setores empresariais.

A Bahia entrou nessa guerra com bastante determinação, através da concessão de pesados subsídios à implantação de novas empresas na Região Metropolitana de Salvador ${ }^{5}$. Além disso, com a recente conquista da Prefeitura da capital pelas forças políticas conservadoras que há décadas dominam o estado, abraçando o paradigma do empreendorismo urbano, os governos estadual e municipal têm desenvolvido um conjunto de ações concertadas para aumentar a "competitividade" da metrópole soteropolitana.

Como destaca Ivo (2001), isto envolve a concentração de investimentos na melhoria das áreas "nobres" e atrativos para o turismo, o incentivo à promoção e profissionalização de grandes eventos culturais e musicais (como o carnaval) e uma intensa utilização da mídia para difundir uma imagem positiva da cidade, apresentando-a como berço da cultura brasileira, lugar excitante, criativo, alegre e humano, bom e seguro para viver, visitar, investir ou consumir. Desviando a atenção dos graves problemas apontados neste texto e deixando em segundo plano as intervenções prioritárias para uma melhoria das comunidades carentes e das condições de vida da população, estas estratégias vêm contribuindo para ampliar a fragmentação, a segregação sócio-espacial e as extremas desigualdades que marcam a paisagem urbana em discussão.

Concluindo, a trajetória de Salvador e de outras metrópoles deixa claro que a reestruturação produtiva está associada a algumas transformações generalizadas, como o declínio relativo do operariado industrial fordista, a terceirização da produção e do emprego, mudanças nas relações de trabalho e precarização com "flexibilidade". Contudo, isto não chega a se traduzir em tendências sócio-econômicas e espaciais universais e inexoráveis nas 
"cidades globais" e, muito menos, nas demais metrópoles dos diversos países e regiões. Em decorrência das diferenças preexistentes e da própria seletividade da globalização, a dinâmica de cada metrópole assume especificidades nacionais e locais.

As análises apresentadas ao longo deste texto também reforçam a conclusão de que a "polarização social" constitui uma perspectiva simplista, que não dá conta da diversidade e da complexidade das mudanças em curso nas grandes cidades. É ilustrativo, a esse respeito, o fenômeno do crescimento dos denominados "informais incluídos", grupo social ao mesmo tempo emergente e "marginal", assim como o processo de reconfiguração das classes médias.

Finalmente, as condições de Salvador são particularmente ilustrativas das conseqüências perversas do padrão atual de abertura e "ajuste" da economia brasileira, mostrando a urgência de uma retomada do desenvolvimento, com estratégias e políticas que compatibilizem a integração internacional com a integração interna, fomentem a coesão e enfrentem a exclusão e as desigualdades sociais e espaciais. Só assim as condições do presente poderão ser superadas, construindo-se um outro e melhor futuro para as nossas metrópoles e sociedades.

Recebido para publicação em setembro/2001

CARVALHO, Inaiá Maria Moreira de; ALMEIDA, Paulo Henrique de \& AZEVEDO, José Sérgio Gabrielli de. Metropolitan dynamics and social structure in Salvador. Tempo Social; Rev. Sociol. USP, S. Paulo, 13(2): 89-114, November 2001.

ABSTRACT: This article discusses how the dynamics of globalization and its aftermath have affected the social economic configuration of Brazilian metropolitan areas, with particular emphasis on the case of Salvador. Following a brief survey of the relevant literature on the subject, the paper links the spatial and urban reconfiguration of the Brazilian metropolitan areas with the historical heritage of the urbanization process, the differentiation of the urban and metropolitan network and the spatial and social effects of recent national policies toward a greater integration with the new international order. The paper compares the recent trends of the socio-economic changes in Salvador with those of other Brazilian metropolises, and concludes that they are not significantly different in spite of a stronger adverse social impact due to local social conditions.
KEY WORDS: metropolitan area, productive restructuring, urban social structure, employment and unemployment. 


\section{REFERÊNCIASBIBUOGRÁFICAS}

Almeida, Paulo H. de \& Azevedo, José Sérgio Gabrielli de. (1999a) Salvador dinâmica: a economia soteropolitana pela ótica da ocupação. Relatório final de pesquisa. Salvador, Faculdade de Ciências Econômicas da UFBa, 129p.

$\&$

. (1999b) Perfil sócio-econômico do trabalho informal de Salvador. Relatório final de pesquisa. Salvador, Faculdade de Ciências Econômicas da UFBa, 101p.

Andrade, Mônica Viegas. (1995) Setor de serviços segmentado - o moderno e o tradicional. Anais do VII Seminário sobre a Economia Minei$r a$, v. 2. Belo Horizonte, UFMG/CEDEPLAR.

AraúJo, Tânia Bacelar de. (1995) Nordeste, Nordestes: que Nordeste. In: Affonso, Rui de Brito Alvares \& Silva, Pedro Luiz Barros (orgs.). Desigualdades regionais e desenvolvimento. São Paulo, FUNDAP, Editora da UNESP, p. 125-156. . (1999) Globalização e regionalização. Brasília, 22 p.

AzEvedo, José Sérgio Gabrielli de. (2000) Economia e mercado de trabalho na Bahia e na RMS: uma abordagem de longo prazo. Bahia, Análise \& Dados. Salvador, SEI, 10: 49-67.

. (2001) Flexible labour and informal sector: some comparisons between the low-paid labour markets in the US, UK and Brazil. Trabalho apresentado no Seminário realizado na Universidade de Reading, United Kingdom. London School of Economics and Political Science, United Kingdom, may.

BELL, Daniel. (1973) The coming of post-industrial society - a venture in social forecasting. New York, Basic Books.

Bogus, Lúcia M. \& Ribeiro, Luiz Cesar de Q. (orgs.). (1999/2000) Desigualdade e governança. Cadernos Metrópole. São Paulo, (1, 2, 3 e 4), PRONEX CNPq/EDUC/FAPESP.

Bonamy, Joël \& May, Nicole. (1994) Services et mutations urbaines: questionnements et perspectives. Paris, Anthropos-Economica.

Borges, Angela \& Filgueiras, Luiz A. M. (1995) Mercado de trabalho nos anos 90: o caso da RMS. Bahia, Análise \& Dados. Salvador, SEI, 5(3): 30-36.

. (1996) As novas tendências do mercado de trabalho formal. Bahia, Análise \& Dados. Salvador, SEI, 6(3): 73-82, dezembro.

BorJa, Jordi \& CASTELs, M. (1997) Local e global. La gestion de las ciudades en la era de la información. Madrid, Taurus.

BRANDÃo, Maria D. de A. (1981) O último dia da criação: mercado, propriedade e uso do solo em Salvador. In: VALLADAREs, Licia do P. (org.). Habitação em questão. Rio de Janeiro, Zahar. 
Carvalho, Inaiá M. M. de \& SouzA, Guaraci A. A. de. (1980) A produção não capitalista no desenvolvimento capitalista de Salvador. In: SouZA, Guaraci A. A. \& FARIA, Vilmar (orgs.). Bahia de todos os pobres. São Paulo, CEBRAP, p. 71-102.

\& PinHo, Antônio J. A. de. (1996) Duas lógicas em conflito: moradia e solo urbano em Salvador. In: RIBEIRO, Luiz Cesar \& AzEVEDO, Sergio (orgs.). A crise da habitação nas grandes cidades brasileiras: da moradia à questão urbana. Rio de Janeiro, UFRJ, p. 189-204.

Cohen, S. \& Zysman, J. (1987) Manufacturing matters: the myth of the post-industrial economy. New York, Basic Books.

Costa, Liduina Farias Almeida da. (2000) O Nordeste e a globalização. Posicionamento dos empresários-políticos cearenses. Fortaleza, 330 p.Tese (Doutorado). Programa de Pós-Graduação em Sociologia da Universidade Federal do Ceará.

Dinız, Clélio Campolina. (2000) Impactos territoriais da reestruturação produtiva. In: RibeIRo, Luiz Cesar (org.). O futuro das metrópoles: desigualdades e governabilidade. Rio de Janeiro, Revan, FASE, p. 21-62.

Franco, Angela, Santos, Elizabete \& Gabrielli, Livia. (1998) Salvador dos novos horizontes. Força de trabalho e emprego. Salvador, 5(2): 21-29, maio-agosto.

HANSEN, Niles. (1994) Le rôle stratégique des services de production dans le développement régional. International Regional Science Review, 16(1-2): 187-195.

IPEA/UNICAMP/IE/NESUB/IBGE. (1999) Caracterização e tendências da rede urbana no Brasil. Coleção Pesquisas 3, vol. 1, Campinas, UNICAMP, IE.

Ivo, Anete Brito Leal (org.). (2001) As metamorfoses da questão democrática: governabilidade e pobreza. Buenos Aires, CLACSO, Coleccion Becas de Investigacion, no prelo.

Lavinas, Lena; Garcia, Eduardo H. \& Amaral, Marcelo R. do. (1997) Desigualdades regionais. Indicadores sócio-econômicos nos anos 90. Rio de Janeiro, IPEA, 47p.

MaldonAdo, Jesus Leal. (2000) Economia, emprego e desigualdade social em Madri. In: RIBEIRo, Luiz Cesar (org.). O futuro das metrópoles: desigualdades e governabilidade. Rio de Janeiro, Revan, FASE, p. 177-204.

Mamarella, Rosetta. (2000) Economia e ocupação no espaço metropolitano: transformações recentes de Porto Alegre. In: RIBEIRO, Luiz Cesar (org.). O futuro das metrópoles: desigualdades e governabilidade. Rio de Janeiro, Revan, FASE, p. 151-175.

Marques, Eduardo \& Torres, Haroldo. (2000) São Paulo no contexto do 
sistema mundial de cidades. Novos Estudos, São Paulo, (56): 139168 , março.

Mattos, Carlos A. (2000) Globalização e metropolização: Santiago, uma história de mudanças e continuidade. In: RiBEIRO, Luiz Cesar (org.). $O$ futuro das metrópoles: desigualdades e governabilidade. Rio de Janeiro, Revan, FASE, p. 121-149.

Philippe, Jean, Léo, Pierre-Yves \& Boulianne, Louis-M. (1998) Services et métropoles: formes urbaines et changement économique. Paris, L'Harmattan.

Preteicelle, Edmond. (2000) Divisão social e desigualdades: transformações recentes da metrópole parisiense. In: RIBEIRO, Luiz Cesar (org.). O futuro das metrópoles: desigualdades e governabilidade. Rio de Janeiro, Revan, FASE, p. 99-120.

REICH, Robert. (1991) The work of nations. New York, Alfred A. Knopf.

Ribeiro, Ana Clara Torres. (2000) Faces ativas do urbano: mutações em um contexto de imobilismo. In: (org.). Repensando a experiência urbana da América Latina: questões, conceitos e valores. Buenos Aires, CLACSO, p. 235-250.

Ribeiro, Luiz Cesar de Q. (2000) Cidade desigual ou cidade partida. Tendências da metrópole do Rio de Janeiro. In: (org.). O futuro das metrópoles: desigualdades e governabilidade. Rio de Janeiro, Revan, FASE, p. 69-98.

SAntos, Milton. (2000) Por uma outra globalização: do pensamento único à consciência universal. Rio de Janeiro, Record.

SASSEn, Saskia. (1991) The global city: New York. London, Tokyo. New Jersey, Princeton University Press.

Soja, Edward W. (1993) Geografias pós-modernas. A reafirmação do espaço na teoria social crítica. Rio de Janeiro, Zahar.

SouzA, Angela Gordilho. (2000) Limites do habitar. Segregação e exclusão na configuração urbana contemporânea de Salvador e perspectivas no final do século XX. Salvador, EDUFBA.

Souza, Celina \& Carvalho, Inaiá Maria M. de. (1999) Reforma do Estado, descentralização e desigualdades. Lua Nova, Revista de Cultura e Política, São Paulo: CEDEC, (48): 187-212.

VeIGA, Danilo. (2000) Notas para uma agenda de investigación sobre processos emergentes en la sociedad urbana. In: RiBEIRo, Ana Clara (org.). Repensando a experiência urbana da América Latina: questões, conceitos e valores. Buenos Aires, CLASCO. 